\title{
O CONHECIMENTO COMO PRODUTO: UMA ANÁLISE DISCURSIVA DAS PROPAGANDAS DE CENTROS UNIVERSITÁRIOS PARTICULARES
}

\author{
ALINE MARIA MIGUEL KAPP-BARBOZA ${ }^{1}$ \\ FERNANDA CORREA SILVEIRA GALLI ${ }^{2}$
}

Instituto de Instituto de Biociências, Letras e Ciências Exatas Universidade Estadual Paulista

Rua Cristóvão Colombo, 2265. Jardim Nazareth. 15054-000 - São José do Rio Preto-SP

aline kapp@hotmail.com ; fcsgalli@hotmail.com

\begin{abstract}
Resumo. $O$ objetivo desta abordagem é compreender os efeitos de sentido dos/nos discursos de propagandas de divulgação de cursos superiores de centros universitários particulares da região de São José do Rio Preto, veiculadas em meio virtual. Com base na perspectiva da Análise do Discurso de linha francesa, analisamos as propagandas de forma a discutir como elas anunciam a oferta de conhecimento por meio de um discurso atravessado por formações discursivas mercadológicas. Levando-se em consideração que os efeitos de sentido são: (i) produzidos na/pela língua, (ii) evidenciados na/pela história, por efeitos ideológicos, e (iii) construídos pelos sujeitos, buscamos, portanto, refletir sobre os deslizamentos de sentido das propagandas por efeito metafórico (PECCHEUX, 1997).
\end{abstract}

Palavras-chave: discurso; sentidos; efeito metafórico; conhecimento.

\begin{abstract}
The aim of this article is to understand the meaning effects of/in the discourses of advertisements of higher education courses of private universities from São José do Rio Preto region, conveyed by a virtual environment. Based on the perspective of French Discourse Analysis we analyze the advertisements in order to discuss how they announce the supply of knowledge through a discourse crossbred by marketing discursive formations. Taking into account that the meaning effects are: (i) produced in/through the language, (ii) evidenced in/by history, by ideological effects and (iii) constructed by the subjects, we seek, therefore, to reflect on the slides of senses of the advertisements caused by metaphorical effect (PECCHEUX, 1997).
\end{abstract}

Keywords: discourse; senses; metaphorical effect; knowledge.

\footnotetext{
${ }^{1}$ Doutora em Estudos Linguísticos pelo IBILCE/UNESP. Professora de língua portuguesa e língua inglesa, vinculada ao Curso de Tecnologia em Gestão de Turismo do IFSP/Barretos.

2 Doutora em Linguística Aplicada pelo IEL/UNICAMP. Professora vinculada ao Programa de Pósgraduação em Estudos Linguísticos do IBILCE/UNESP. Bolsista de pós-doutorado do PNPD/CAPES.
} 


\section{INTRODUÇÃO}

O Ensino Superior privado no Brasil responde hoje por $75 \%$ das matrículas. Esse predomínio é marcado por diferentes acontecimentos históricos, os quais foram influenciados não apenas por mudanças econômicas, mas também pela entrada em vigor da Constituição da República, de 1891, que viabilizou a existência do setor privado na Educação Superior, e da Constituição de 1988, que, inspirada pelo princípio liberal da época, preservou o Ensino Superior livre à iniciativa privada, respeitando as legislações e as avaliações do poder público referentes à educação. No decorrer de seu estabelecimento no cenário educacional, o setor privado passou por diversas mudanças e hoje, dada sua preocupação com a demanda do mercado, busca constantemente estratégias para atrair e manter consumidores em potencial. Assim, as propagandas representam uma ação bastante eficaz nessa busca.

O discurso publicitário busca moldar a identidade dos leitores mediante percepções de uma realidade sócio-político-economicamente condicionada. Dentro de uma perspectiva consumista, esse discurso, desenvolvido, reproduzido e transformado nas práticas sociais midiáticas, tende a alcançar seu objetivo por meio da doutrinação, do controle cultural e das construções ideológicas da percepção (KEY, 1996 apud MAGALHÃES, p. 241). A Análise do Discurso (AD) de linha francesa tem muito a contribuir para essa discussão, uma vez que é de interesse da AD compreender como os processos discursivos são constituídos, a partir das noções de língua e de história como não transparentes. Dada a sua constituição, a AD nos possibilita refletir sobre os atravessamentos ideológicos materializados nas propagandas, bem como compreender o modo como a ideologia interpela o indivíduo em sujeito.

As propagandas, como sabemos, utilizam diversas estratégias para interpelar seu público-alvo e, nessa dinâmica, é interessante notar o quanto as instituições de ensino, cada dia mais, fazem uso desse artifício em busca da obtenção de lucro. Nesse intento, o que deveria ser apresentado como um processo simbólico acaba sendo ofertado como um produto a ser adquirido. Esse cenário motivou-nos a investigar ${ }^{3}$ um conjunto de propagandas de divulgação de cursos universitários da região de São José do Rio PretoSP que nos possibilitasse a compreensão dos efeitos metafóricos que instalam o dizer no jogo das diferentes formações discursivas ${ }^{4}$ (FD), representando, assim, um vestígio da historicidade. Nosso objetivo, portanto, é compreender, os efeitos de sentido dos/nos discursos das propagandas dessas instituições e refletir a respeito dos deslizamentos de sentidos por efeito metafórico (PÊCHEUX, 1997 e ORLANDI, 2001). Para tanto, selecionamos propagandas veiculadas pela internet, mais especificamente nos sites e páginas de redes sociais oficiais desses estabelecimentos educacionais.

\footnotetext{
${ }^{3}$ Esse artigo é resultado do Exame de Qualificação Especial de Doutorado desenvolvido no Programa de Pós-graduação em Estudos Linguísticos do IBILCE/UNESP, na linha de pesquisa "Oralidade e Letramento".

${ }^{4}$ Apropriando-se da noção de formação discursiva de Foucault e a ressignificando no campo da Análise do Discurso francesa, Pêcheux (1997, p. 188) a define como "aquilo que pode e deve ser dito (articulado sob a forma de uma arenga, de um sermão, de um panfleto, de uma exposição, de um programa, etc.) a partir de uma posição dada na conjuntura social". Em outras palavras, as FD podem ser definidas como "a projeção, na linguagem, das formações ideológicas. As palavras, expressões, proposições adquirem seu sentido em referência às posições dos que as empregam, isto é, em referência às formações ideológicas nas quais as posições se inscrevem" (ORLANDI, 2006, p. 17).
} 
Para desenvolver essa reflexão, apresentamos, primeiramente, um breve percurso acerca da constituição da Análise do Discurso de linha francesa; em seguida, buscamos refletir sobre os deslizamentos de sentido por efeito metafórico (PÊCHEUX, 1997 e ORLANDI, 2001) nas propagandas de divulgação de cursos superiores das instituições de Ensino Superior privadas. Entendendo que a interpretação é materializada na/pela história, apresentamos também um percurso histórico sobre o estabelecimento dessas faculdades no cenário educacional.

\section{ANÁLISE DO DISCURSO DE LINHA FRANCESA: DA LÍNGUA AO DISCURSO}

Proposta por Michel Pêcheux nos anos 60, na França, e desenvolvida por Eni Orlandi no final da década de 70, no Brasil, a Análise de Discurso (doravante AD) de linha francesa, constituída na interface com os campos do saber da Linguística, do Marxismo e da Psicanálise, postula que a linguagem está relacionada à sua exterioridade e a concebe como uma "mediação necessária entre o homem e a realidade natural e social" (ORLANDI, 2001, p. 15), de maneira que o sujeito, por ser afetado pela história, pelo inconsciente e pela ideologia, é comprometido com o sentido e com o político. Dessa articulação com outros campos epistemológicos, noções já cunhadas, ao serem incorporadas à teoria, ganham novo escopo e relevância. Dentre elas, destaca-se a noção de língua, que, como ocorre em outras teorias, afeta a forma como o analista concebe outros conceitos essenciais para a teoria e também guia seus procedimentos de análise. Tomada como relativamente autônoma, passível de equívocos, falhas e mal-entendidos, lugar material de produção de processos discursivos, a noção de língua para a AD afeta consequentemente o modo como os conceitos de história, sentido, sujeito e ideologia são concebidos:

como numa reação em cadeia, os traços definidores da língua, como o fato de ser apenas relativamente autônoma, afetam, por exemplo, a condição do sujeito, que não é mais a origem de si; o sentido, que não é conteúdo; a história, que não é contexto, e a ideologia, que não é defeito. (FERREIRA, 2003, p. 199)

Lugar de funcionamento ideológico, a língua, que, dada sua opacidade, envolve o equívoco, pode ser definida, portanto, como a materialidade específica do discurso, que, por sua vez, é a materialidade específica da ideologia. Tal concepção, segundo Ferreira (2003, p. 197), é fundamental para tecer a cadeia discursiva e, por consequência, reflete no trabalho do analista de discurso, que toma a língua não como seu principal objeto de investigação, mas como um pressuposto fundamental para analisar a materialidade do discurso. É na língua, portanto, que se materializam os deslizamentos de sentido, os lapsos e os mal-entendidos. Conforme defende Pêcheux (1997), a língua é considerada relativamente autônoma na medida em que, além de apresentar funcionamento fonológico, morfológico e sintático, está comprometida com processos discursivos dos mais diversos. Tal concepção surge como uma crítica do autor para com a ideia de que a língua possui a função de expressar o sentido ou ser instrumento para a comunicação.

Da perspectiva da $\mathrm{AD}$, ser relativamente autônoma remete ao lugar material que a língua ocupa enquanto sustentação para o desenvolvimento dos processos discursivos 
constitutivos do sentido, os quais representam um suporte abstrato que sustenta os diferentes textos, realizações concretas do discurso, que circulam em nosso meio. Vale ressaltar que, mesmo sendo considerada uma unidade empírica de análise, o texto não pode ser apenas entendido como um lugar de análise de conteúdo; é, além disso, um lugar em que a materialidade histórica da linguagem se faz presente, ou seja, conforme afirma Orlandi (2012, p. 61), "um texto é uma peça de linguagem de um processo discursivo muito mais abrangente". $\mathrm{Na}$ ordem da formulação, o texto é concebido como a manifestação concreta do discurso, ao passo que o discurso, na ordem da constituição, é concebido como a materialidade específica da ideologia. Com base nessas definições, Orlandi (2000, p. 55) afirma que o discurso não é um conjunto de textos e sim uma prática, uma vez que o que se busca são os processos de produção e não os produtos.

Ao criticar o esquema de comunicação proposto por Jakobson, Pêcheux (1997) defende que o discurso vai muito além da mera transmissão de uma mensagem linear, compreendida de maneira transparente pelos interlocutores em uma relação de estímulos e respostas. Para Pêcheux (1997), o discurso é entendido como "efeito de sentidos entre locutores", e essa relação de sentido entre locutores não é linear, muito menos transparente; ela está relacionada, necessariamente, com a exterioridade, com a formação ideológica de cada interlocutor e com as condições de produção histórico-sociais (ORLANDI, 2006, p. 14-15). Com isso, o texto é visto pela AD como uma unidade que permite o acesso ao discurso, por isso é tido como um objeto simbólico de interpretação. Sobre a relação de convergência e divergência existente entre as noções de texto e discurso, Orlandi esclarece que:

a relação entre texto e discurso não é biunívoca (um discurso não é igual a um texto e vice-versa). Por outro lado, o texto é uma unidade de análise, mas não é unidade de construção do discurso. Nem por isso deixa de ser um conceito mediador imprescindível: a unidade de construção do discurso é o enunciado, mas ele tem de ser referido ao texto para poder ser apreendido no processo de construção do discurso. (ORLANDI, 2000, p. 59)

Ao tratar da distinção entre essas duas noções, a autora esclarece que o tipo de discurso jornalístico, por exemplo, pode ser materializado por meio de múltiplos textos de diferentes formações discursivas. Mesmo podendo apontar diferenças, não há como olhar para o texto e concebê-lo como unidade fechada, já que, dada sua relação com o discurso, o texto é atravessado por várias posições de sujeito, fato que reflete em sua diferença constitutiva. Isso significa dizer que ele se difere quanto à imagem, grafia, som; quanto à natureza da linguagem; quantos às posições assumidas por seus sujeitos; e quanto às diferentes formações discursivas por ele evocadas (ORLANDI, 2012, p. 59). Nessa perspectiva, "o texto é a unidade de análise afetada pelas condições de produção", "é o lugar da relação com a representação física da linguagem: onde ela é som, letra, espaço, dimensão direcionada, tamanho. É o material bruto. Mas é também espaço significante (ORLANDI, 2012, p. 60).

Não é o texto o objeto de análise da AD, mas é por meio dele que as condições de produção se manifestam e, em um processo de dessuperficialização, é possível converter um dado empírico em um objeto teórico - o discurso, o objeto de análise da AD. É o discurso, portanto, que viabiliza a observação das relações entre ideologia e língua e seus 
efeitos, e permite a compreensão de como os sentidos são produzidos e como os sujeitos são constituídos. Assim, o discurso deve sempre remeter às relações de sentido nas quais é produzido, referindo-se, como consequência, a outros discursos, aos já-ditos. Essa característica do discurso conduz Pêcheux a afirmar que o processo discursivo não tem, de direito, início:

o discurso se conjuga sempre sobre um discurso prévio, ao qual ele atribui o papel de matéria-prima, e o orador sabe que, quando evoca tal acontecimento, que já foi objeto de discurso, ressuscita no espírito dos ouvintes o discurso no qual este acontecimento era alegado, com as "deformações" que a situação presente introduz e da qual pode tirar partido. (PÊCHEUX, 1977a, p. 77)

É importante ressaltar que o discurso não é reflexo da situação, mas, dado o fato de que une língua e história, o discurso causa impressão de realidade, assegurando a manutenção de uma representação dessa realidade. Como já mencionado, língua e discurso têm materialidades distintas, porém, intercomplementares: a primeira representa uma materialidade necessária para a realização da ideologia; enquanto que o segundo remete aos lugares em que essas ideologias são colocadas em prática, produzindo, assim, determinados efeitos de sentido, reflexos de determinadas ordens histórico-simbólicas (ZANDWAIS, 2009, p. 22). Desse modo, pode-se afirmar que é por meio da língua que se percebe o processo de produção de sentido, o qual pode ser definido ao levarmos em consideração diferentes áreas do conhecimento (a saber, a teoria da sintaxe e da enunciação; a teoria da ideologia; e a teoria do discurso). Assim, a articulação dessas teorias juntamente com uma teoria do sujeito de natureza psicanalítica faz com que a noção de sentido para a $\mathrm{AD}$ seja entendida como algo relacional.

Tendo como base essa noção de sentido, a Análise de Discurso propõe uma crítica à noção de leitura e de interpretação, problematizando a relação do sujeito com o sentido e, como consequência de sua abordagem, da língua com a história. A esse respeito, Orlandi afirma:

a Análise do Discurso não estaciona na interpretação, trabalha seus limites, seus mecanismos, como parte dos processos de significação. Também não procura um sentido verdadeiro através de uma "chave" de interpretação. Não há esta chave, há método, há construção de um dispositivo teórico. Não há uma verdade oculta atrás do texto. Há gestos de interpretação que o constituem e que o analista, com seu dispositivo, deve ser capaz de compreender. (ORLANDI, 2002, p. 26)

A compreensão, para a $\mathrm{AD}$, envolve o conhecimento de como um objeto simbólico produz sentidos, de como as interpretações funcionam. Assim, o processo de compreender permite explicitar as significações presentes em um texto, além de sugerir outros sentidos constituídos naquele discurso para e por sujeitos. São essas significações que buscamos discutir na análise de propagandas veiculadas na internet por centros universitários particulares da região de São José do Rio Preto-SP. 


\section{AS PROPAGANDAS: UMA ANÁLISE DISCURSIVA}

Frequentemente presentes no nosso cotidiano, as propagandas, uma das maiores forças no cenário da comunicação empresarial, objetivam persuadir seus consumidores a agirem de uma determinada forma pré-estabelecida, com o intuito de aumentar o faturamento de alguma empresa ou de aproximar o consumidor de determinado produto. A publicidade, muito procurada em períodos de recessão comercial, surge como uma estratégia eficaz no processo de constituição de um mercado de consumo, uma vez que sua presença é fundamental no processo de constituição de sujeitos consumidores, ou seja, no processo de interpelação do sujeito à condição de consumidor (DELA-SILVA; CRUZ, 2015). Além das propagandas comerciais, há as não comerciais ou de ideias, ou seja, as propagandas institucionais ou governamentais, cujo intuito normalmente é, conforme se 'vende' o discurso, a conscientização acerca de algum assunto. No cenário educacional governamental, por exemplo, há muitas propagandas que são veiculadas, aparentemente, com o propósito de conscientizar e informar os cidadãos a respeito de programas, provas e/ou resultados do governo (CAMPOS-TOSCANO, 2009, p. 49-50). No entanto, da perspectiva discursiva, essa aparente neutralidade da linguagem direcionada a um sujeito concebido cognitivamente (e não historicamente construído) é uma ilusão. Nesse sentido, ao levar em consideração a projeção de um sujeito consumidor, a linguagem publicitária produz efeitos de necessidade e desejo, buscando criar e satisfazer expectativas já existentes, e, por isso, parece manifestar um forte apelo a fatores emocionais (PEREIRA, 2006 , p. 15). Esse funcionamento ocorre por meio da argumentatividade, que instala o discurso em um campo político, constituído pelo polêmico; dito de outro modo, as empresas do ramo educacional, por meio de suas propagandas, oferecem um produto pronto, a ser consumido socialmente, o que emerge enquanto efeito da informação.

Na busca de eficácia nessa empreitada, o discurso publicitário cria não só necessidades materiais, como também sociais, ou seja, necessidades que despertam nos consumidores, ao adquirem determinado produto, um desejo de encontrar bem-estar, felicidade, admiração, aceitação em determinado grupo etc. (CAMPOS-TOSCANO, 2009 , p. 50). Com o intuito de satisfazer os anseios de grande parte da população, as propagandas são veiculadas por diferentes meios: as que aqui analisamos circulam em sites e redes sociais (como Facebook) oficiais dos diferentes centros universitários. No entanto, verificamos que elas também são veiculadas na televisão, por meio de vídeos que abordam a mesma temática dos banners. Uma vez que o anúncio televisivo pode atingir todo e qualquer tipo de público, assim como a internet, os produtos nele ofertados caracterizam também um consumo de massa. Com base nessa perspectiva do consumo, elegemos algumas peças publicitárias para análise, nas quais vemos emergir a questão do conhecimento como "algo a ser vendido e/ou procurado", ou seja, como "produto", tanto para o fornecedor quanto para o cliente.

No processo de compreensão dos efeitos de sentido, levamos em consideração a ideologia que constitui os discursos e as condições de produção das propagandas, elementos essenciais ao processo de análise em AD. No que diz respeito ao processo de análise, Orlandi (2012, p. 59) destaca que o texto deve ser considerado como um discurso e não como um documento, o que faz com que o processo de descrição e interpretação considere, também, a memória como crucial para entender como os sentidos são produzidos. Assim, é necessário distinguir a noção de "dado" - um objeto da organização linguística do texto, da noção de "fato" - um objeto da ordem do discurso, uma vez que 
é por meio do "fato" que se adentra a memória da linguagem, compreendendo toda sua historicidade, sistematicidade e funcionamento. É importante ressaltar também que, independentemente dos procedimentos de análise, "o sentido sempre pode ser outro e o sujeito (com suas intenções e objetivos) não tem o controle daquilo que está dizendo". Portanto, compreendido como um caminho de acesso ao discurso, ou seja, materialidade específica da ideologia, o texto, bem como os inúmeros "fatos" que dele se emergem, é considerado objeto concreto de análise da AD. Isso posto, buscamos não só analisar a materialidade do texto - as propagandas, mas também compreender o contexto de criação e expansão das instituições privadas de Ensino Superior no Brasil para, então, refletirmos sobre os "fatos".

Em discussão sobre o crescimento do financiamento privado no Ensino Superior no Brasil, a antropóloga e professora da Faculdade de Educação da Unicamp, Helena Sampaio (2011), faz um percurso histórico sobre o surgimento e a manutenção do setor privado na educação superior. Nessa trajetória, destaca-se a segunda metade do século XX como o início do desequilíbrio da relação entre Ensino Superior público e privado, levando em conta a quantidade de instituições e o número de matrículas. No início dos anos 1970, a sociedade brasileira, cada vez mais urbana e industrializada, começou a demonstrar interesse no Ensino Superior, na busca de realização pessoal e ascensão profissional. Assim, a iniciativa privada, diagnosticando essa nova demanda e enxergando nela consumidores em potencial, investiu rapidamente no mercado, o que levou a uma grande expansão das instituições de Ensino Superior privadas. A esse respeito, a autora afirma:

o setor privado, mobilizando recursos privados e orientando-se para atender à demanda de mercado, foi mais dinâmico e cresceu mais rapidamente que o público, muitas vezes em detrimento da própria qualidade do serviço oferecido. Entre 1960 e 1980, o número de matrículas no Ensino Superior passou de 200 mil para 1,4 milhão, em um crescimento de quase $500 \%$; no setor privado, o crescimento foi de mais de $800 \%$. (SAMPAIO, 2011, p. 29)

Esses números são reflexos do tipo de investimento que cada setor realizava: à medida que o setor privado criava instituições e aumentava o número de cursos e vagas que eram oferecidos, o setor público dedicava-se ao investimento em pesquisa e estrutura para oferta de cursos de pós-graduação (SAMPAIO, 2011, p. 29). Após o período de recessão econômica dos anos 1980, marcado por uma transição democrática lenta e gradual e por uma economia estagnada, o final do século XX marca o início de ações empreendedoras por parte das empresas privadas, no sentido de reaquecer o mercado e adequar-se às legislações estabelecidas pelo estado. Houve, então, um interesse muito grande dessas instituições privadas em se tornar universidades, uma vez que a Constituição de 1988 havia instituído o princípio de autonomia para as universidades. Assim, o setor privado estaria livre do controle burocrático do antigo Conselho Federal de Educação (CFE), livre para criar e extinguir cursos, remanejar as vagas oferecidas, dentre outras ações.

Diante desse cenário, entre 1985 e 1996, o número de instituições particulares mais do que triplicou. Com maior diversificação na oferta de cursos e desconcentração regional, o setor privado cresceu mais no interior do que nas capitais. Orientada pelo e 
para o mercado, uma estratégia bastante empregada nesse período foi a "fragmentação de carreiras", nomeada e definida por Sampaio (2011, p. 31) como "a transformação de uma habilitação e/ou disciplina em carreira independente". Houve, ainda, mais uma mudança na esfera educacional privada no Brasil: o decreto 2306, de 19 de agosto de 1997. Em seu artigo $1^{\circ}$, estabeleceu que as instituições podem optar por assumir natureza civil ou comercial, classificando-se, a depender da escolha, em entidade mantenedora de instituição sem finalidade lucrativa e entidade mantenedora de instituição particular com finalidade lucrativa.

O caminho pelo qual esses estabelecimentos educacionais percorreram reflete no tipo de ensino ofertado atualmente e, por consequência, nas estratégias publicitárias empregadas para a divulgação de seus cursos, vestibulares etc. Esse percurso de expansão das instituições privadas é marcado, primeiramente, pela contratação de consultores/assessores, que normalmente vinham do setor público, para tratar de assuntos acadêmicos, como implantação de cursos de pós-graduação lato sensu e stricto sensu; elaboração de projetos de extensão; criação de grupos de pesquisa, dentre outras atividades exercidas pelas universidades públicas. Mais recentemente, conforme afirma Sampaio (2011), as preocupações acadêmicas foram cedendo lugar a outros interesses: havia a necessidade de consultores especialistas na área de gestão, negócios e marketing.

Nos primeiros anos do século XX, houve uma desaceleração desse crescimento, ocasionada pelo fato de a demanda efetiva ser menor do que o sistema de Ensino Superior privado. Essa conjuntura levou a mais uma mudança de estratégia: o foco na busca daqueles estudantes que não procuravam pelo Ensino Superior. Para tanto, a estratégia de regionalização e interiorização de oferta foi intensificada, e obteve resultados bastante prósperos. Atualmente, as instituições privadas representam $90 \%$ do total de estabelecimentos de Ensino Superior do Brasil. Outro aspecto que auxiliou na expansão dessas instituições foi investir não apenas em cursos de graduação, buscando no mercado suas próximas ações, sejam elas de caráter acadêmico, sejam elas de caráter mercadológico:

\begin{abstract}
o setor privado reconhece uma demanda difusa por conteúdos também difusos de conhecimento - jovens que concluíram o ensino médio, mas que ainda não se dirigiram para o Ensino Superior, evadidos do primeiro curso superior, egressos da graduação, trabalhadores em ascensão, desempregados, ansiosos e insatisfeitos de todas as idades que o leva a explorar ao máximo a sua elasticidade, colocando no mercado pacotes de conhecimentos que podem ser consumidos de forma moderada ou compulsivamente por públicos de origens, idades, formações e interesses muito heterogêneos. Nesse quadro, ganham destaque especialmente os cursos de pós-graduação lato sensu presenciais ou de ensino a distância. (SAMPAIO, 2011, p. 39; grifo nosso)
\end{abstract}

Essa busca contínua por alunos leva as instituições a sempre inventar maneiras de manter esse público por perto, maneiras essas que, nos últimos tempos, levaram o âmbito da produção de conhecimento para o do consumo, ou seja, a publicidade regula para a universidade enquanto empresa uma determinada significação: a universidade não é mais um espaço de produção de conhecimento, mas um lugar que parece delimitar e transferir pacotes de conhecimento enquanto "bens de consumo". Essa oferta de produtos, segundo 
Sampaio, "parece efetivamente induzir e manter de forma contínua a demanda por educação". Como podemos verificar, nessa forma de administrar, pautada pelo capitalismo contemporâneo, os rumos da educação superior ofertada pelas instituições de ensino privadas vão de encontro às ambições de mercado. Levando em consideração o contexto de instauração das instituições privadas, a noção de metáfora, entendida pela Análise do Discurso como uma transferência, é de extrema relevância para as leituras das peças publicitárias selecionadas para análise. Dessa forma, por meio dos efeitos de sentido, há a evocação de imagens e conceitos inscritos na memória discursiva, remetendo-as, na forma de discursos transversos, ao interdiscurso, e ressignificando, assim, o enunciado. A noção de metáfora é definida por Pêcheux da seguinte forma.

\begin{abstract}
Chamaremos efeito metafórico o fenômeno semântico produzido por uma substituição contextual para lembrar que esse "deslizamento de sentido" entre x e y é constitutivo do "sentido" designado por x e y; esse efeito é característico dos sistemas linguísticos "naturais", por oposição aos códigos e às "línguas artificiais": em outros termos, um sistema "natural" não comporta uma metalíngua a partir da qual seus termos poderiam se definir: ele é por si mesmo sua própria metalíngua. (PECHEUX, 1997, p. 96)
\end{abstract}

Para o autor, a metáfora, presente em todo o processo de produção de sentido, é entendida como um efeito de sentido instituído pela posição (social, cultural, histórica) do sujeito enquanto enuncia, ligado à ideologia, à memória discursiva e à rede de sentidos construídos pelo interdiscurso. Esse efeito permite deslocamentos de sentido, uma vez que possibilita que um efeito semântico seja substituído contextualmente por outro, sem se desligar dele totalmente. Essa transferência de sentidos, segundo Orlandi (2001), permite que percebamos a não-literalidade desses sentidos, uma vez que, a depender das formações discursivas em que estiverem inseridas, palavras iguais podem ter significados diferentes.

Para a presente reflexão, selecionamos cinco peças publicitárias de centros universitários diferentes. $O$ critério para a seleção pautou-se na observação de propagandas que ofereciam conhecimento com diferentes estratégias persuasivas e direcionadas a (possíveis) diferentes públicos consumidores. A partir desse material, buscamos refletir acerca dos discursos que se entrelaçam, se repetem, se interpelam, remetendo, assim, ao interdiscurso, "lugar de encontros e confrontos de sentido", conforme afirma Gregolin (2003, p. 50). Conforme procuramos demonstrar, esse deslizamento de sentido ocorre tanto em uma mesma formação discursiva, quando compreendemos, na relação do dito com o não-dito, 'conhecimento' como paráfrase de 'ensino', como de uma formação discursiva para outra, quando o discurso publicitário se sobrepõe ao discurso pedagógico, por exemplo. Essa sobreposição produz determinados efeitos de sentido, como a ideia de que o aluno/aprendiz vai perdendo cada vez mais espaço para o consumidor. Vejamos o primeiro recorte, a seguir. 


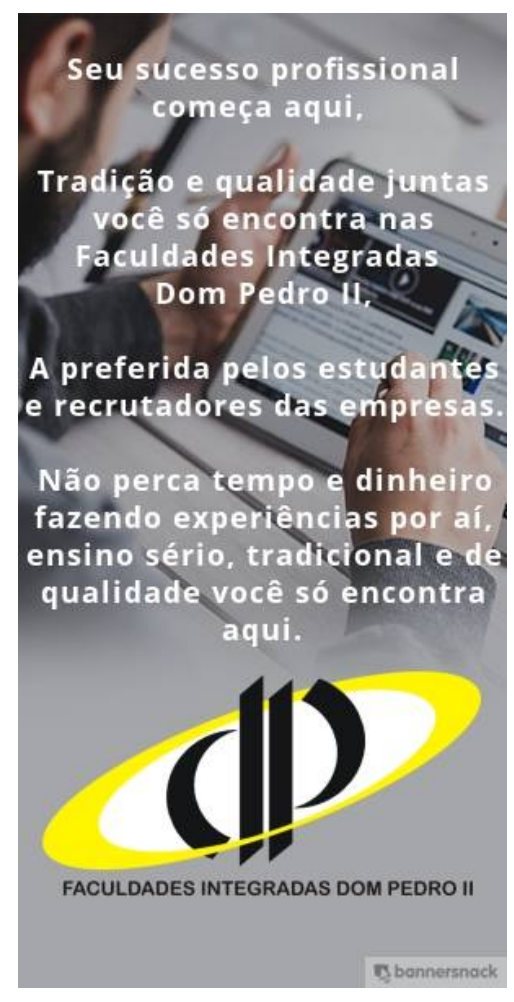

Faculdades Integradas Dom Pedro II ${ }^{5}$.

Nessa primeira peça publicitária, notamos que o foco está em relacionar conhecimento a algo tradicional e de qualidade, o qual pode levar o aluno ao sucesso profissional. Ao atribuir o adjetivo "tradicional" ao ensino, é possível notar, como um dos sentidos possíveis, a oposição implícita ao ensino a distância, bastante difundido atualmente entre os diversos centros universitários. A compreensão dessa oposição pode ser depreendida a partir do não-dito, que é construído por um processo histórico, de remissão e pelos sentidos que vêm pela memória discursiva. $\mathrm{O}$ enunciado "Tradição e qualidade juntas você só encontra nas Faculdades Integradas Dom Pedro II" parece veicular uma exclusividade dessa faculdade, evidenciada pelo uso do advérbio "só", em oferecer, ao mesmo tempo e no mesmo lugar, ensino tradicional e de qualidade, confrontando o discurso corrente na sociedade que questiona a qualidade de ensino oferecido pelas faculdades particulares. A busca, hoje, pelo Ensino Superior é motivada prioritariamente pela oportunidade de ascensão profissional, de maneira que, ao prometer sucesso profissional, a instituição atinge a expectativa de seu público. Relacionar esse sucesso ao fato de que a faculdade é a preferida pelos recrutadores de empresas leva a crer que há uma garantia de contratação logo ao término do curso. A imagem apresentada ao fundo da peça publicitária tende a corroborar com essa ideia de sucesso profissional, já que há a presença de um homem, vestindo algo formal, fazendo uso de um tablet.

É pelos efeitos metafóricos que percebemos a emergência do interdiscurso mercadológico, com a oferta de um produto, reforçado principalmente pela associação deste com o tempo e o dinheiro, medidas fundamentais nesse tipo de interdiscurso. Assim, notamos um deslizamento de sentido: não perder tempo e dinheiro ao procurar um curso

\footnotetext{
${ }^{5}$ Disponível em:

https://www.facebook.com/faculdadesdompedro/photos/a.1123416177720229.1073741827.12448687094 6503/1134252316636615/?type=3\&theater. Acesso em 29 jun. 2017.
} 
superior traz ao novo discurso um novo efeito de sentido ao sugerir que o que a população busca é o sucesso imediato. Esse imediatismo e esse tiro certeiro são típicos de negociações, o que confirma a afirmação de Sampaio (2011) de que o foco das instituições é colocar no mercado pacotes de conhecimento para serem consumidos, fato que promove um apagamento do discurso de conhecimento como processo, como algo a ser construído em tempos e modos diferentes. Mesmo empregando palavras que indicam processo, como é o caso da palavra "ensino", o que implica em uma neutralidade da linguagem, o sujeito consumidor é convocado nesses discursos atravessados e nesses deslizamentos de sentido.

Em relação ao uso de estratégias persuasivas, podemos também notar a oposição entre os significantes "experiências" e "ensino"; enquanto, para a Faculdade Dom Pedro II, o que é oferecido pelas concorrentes são experiências (uma possível paráfrase de tentativas), o produto que oferece é ensino. Entretanto, o sentido desse ensino como instrução/educação tem outro tom, talvez de enfraquecimento, à medida que o discurso mercadológico atravessa o discurso educacional. Da mesma forma, uma das propagandas apresentadas pela Faculdade FACMIL/Uniesp, de São José do Rio Preto, também associa conhecimento ao sucesso, oferecendo "Conhecimento que é porta para o sucesso", o que é sugerido também pelo trecho de uma notícia divulgada no site da instituição, a seguir transcrito:

Se estudar é um investimento e se nas Faculdades UNIESP esse investimento resulta em formação com qualidade de ensino e sem perda de tempo, seu retorno será vantajoso não apenas em termos financeiros, mas principalmente pelo sucesso que o conhecimento trará ao seu investidor. Assim sendo, no GRUPO EDUCACIONAL UNIESP, tempo é muito mais que dinheiro. (grifo nosso; fonte: Notícia FACMIL ${ }^{6}$ )

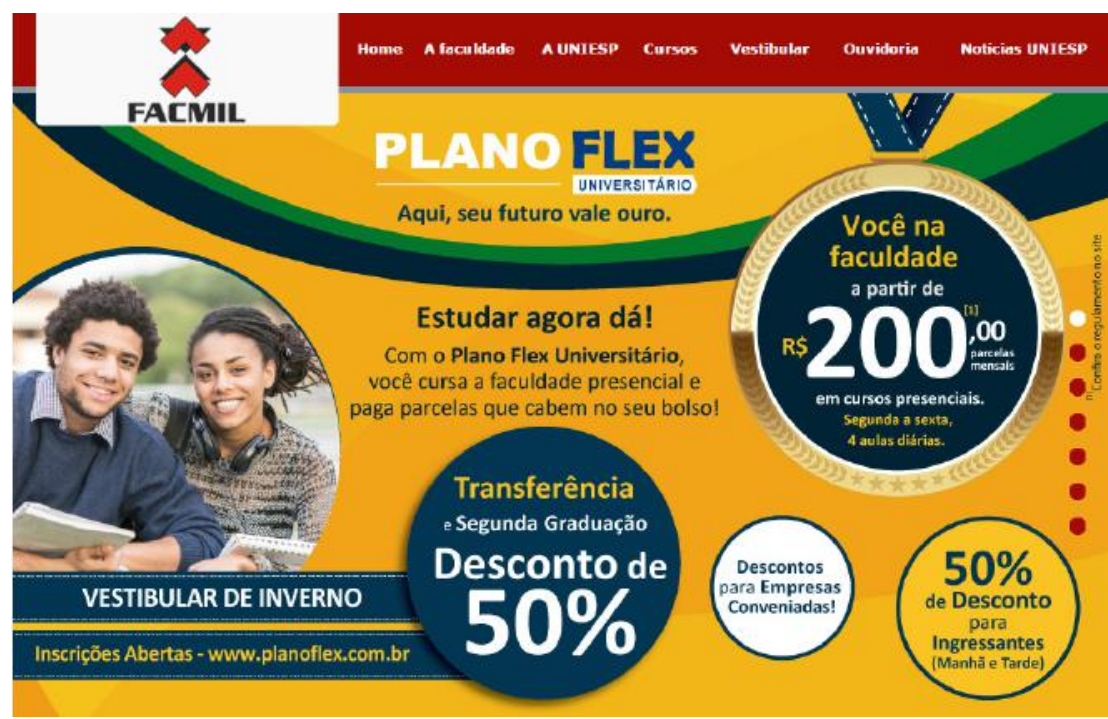

Página da ACMIL7.

\footnotetext{
${ }^{6}$ Disponível em: http://www.facmil.edu.br/noticiasFacmilVisualizar.asp?noticia=10941. Acesso em 29 jun. 2017.

${ }^{7}$ Disponível em: http://facmil.edu.br/. Acesso em 29 jun. 2017.
} 
Pela notícia e pela peça publicitária, é possível também identificar um deslizamento de sentido quanto à noção de conhecimento. Ao trazer para o discurso educacional significantes como "investimento", "vantajoso", "financeiro", "dinheiro", próprios do discurso mercadológico, há uma ênfase na ideia de conhecimento como produto. Mais uma vez, há a associação entre tempo e dinheiro, mas, nessa ocorrência, há a comparação entre os dois apresentando o tempo como superior a dinheiro, ou seja, destaca-se o investimento pessoal que se faz para se obter sucesso em detrimento do investimento financeiro. Afirmar que estudar é um investimento traz ao "novo" discurso um sentido diferente, entretanto não se desvincula totalmente de se seu sentido já naturalizado, o de empregar capital. Com o objetivo de angariar alunos, essas faculdades buscam facilitar ao máximo as formas de pagamento, o que pode ser notado na afirmação "Estudar agora dá", em que a presença do advérbio temporal "agora" pressupõe que houve um tempo em que não era possível que todos estudassem, tempo esse diferente do atual. Essa afirmação suscita alguns pré-construídos, que se diferenciam dos pressupostos por estarem ligados à história e não apenas à língua. Assim, ao afirmar que "agora" é possível estudar, o discurso veiculado por essa instituição educacional pode sugerir que a impossibilidade de se graduar estava relacionada ao fato de não existir universidades particulares, ou ao fato de o sujeito consumidor não ter tido contato com essa faculdade anteriormente, seja por desconhecimento ou pela inexistência dela até certo tempo atrás, ou ainda por não tido até então amparo financeiro (como os financiamentos e as bolsas de estudo) para poder se dedicar ao curso, uma vez que, além de financiamentos próprios, as referidas instituições, oferecem descontos aos conveniados e a empresas parceiras.

Esses convênios, associações e parcerias com as empresas dão maior credibilidade na garantia de que seus alunos poderão alcançar o sucesso profissional que tanto almejam. A União das Faculdades dos Grandes Lagos (Unilago) de Rio Preto também traz um discurso direcionado para o mercado de trabalho, que oferta "Conhecimento insuperável, que derruba barreiras, preparando o aluno para o mercado de trabalho", como podemos notar no banner e no texto retirado de um vídeo de divulgação, a seguir apresentados:

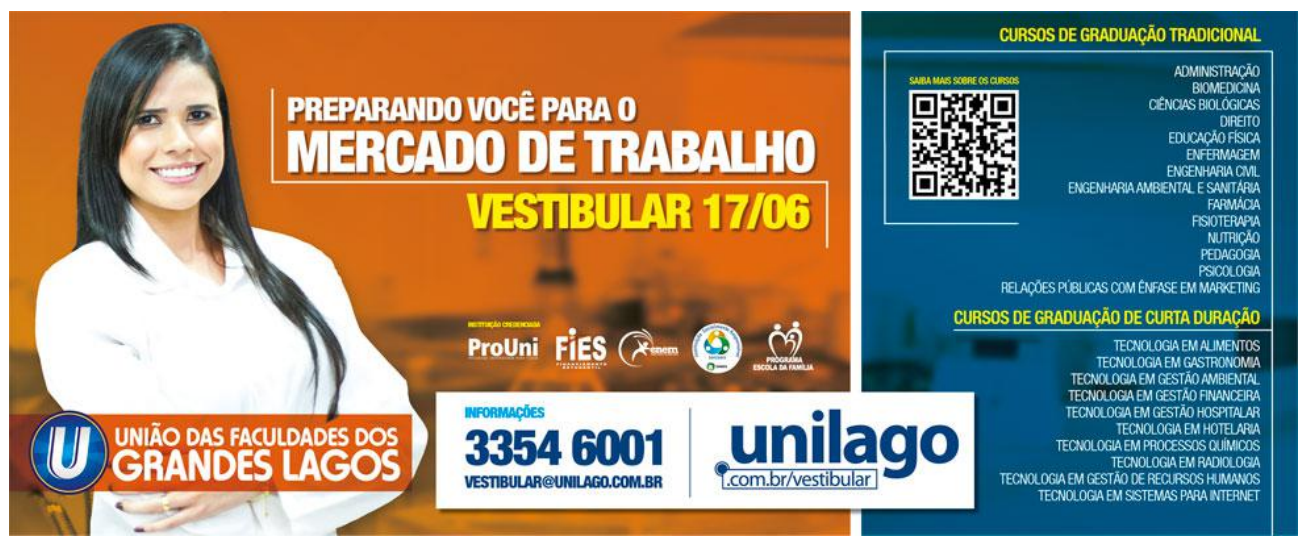

Página da UNILAGO no Facebook?

\footnotetext{
${ }^{8}$ Disponível em:

https://www.facebook.com/UnilagoOficial/photos/a.230740223694124.38312.100359856732162/230740 $227027457 /$ type=3\&theater. Acesso em 29 jun. 2017.
} 
No vídeo de divulgação, veicula-se a seguinte mensagem.

O futuro bem sucedido e o conhecimento caminham juntos, fazendo os sonhos se tornarem realidade. O seu futuro alicerçado por um bom conhecimento derruba barreiras e constrói uma carreira de sucesso. Tudo que você deseja, quando bem planejado, se torna muito mais simples do que se pode imaginar. Vestibular tradicional 2016 Unilago. Nada supera o conhecimento.

Destacamos, nessa peça publicitária, o discurso de mentor apresentado no texto acima. Há, mais uma vez, um atravessamento com o interdiscurso administrativo, mercadológico, ao sugerir que, com um bom planejamento de vida e gestão do tempo, é possível alcançar tudo o que se deseja. O conhecimento insuperável oferecido pela Unilago aparece aliado a um futuro bem-sucedido, a uma carreira de sucesso, justificando o tom de conselho que é dado na divulgação de seus cursos, com o objetivo de persuadir seu público a aderir à sua mercadoria, ao seu pacote de conhecimento. Em outras palavras, ao adquirir o conhecimento oferecido por esse centro universitário, o consumidor leva também um futuro bem-sucedido. $\mathrm{O}$ destaque dado no texto divulgado a "mercado de trabalho", juntamente com a imagem de alguém aparentemente já formada, reforça esse foco no ambiente profissional. Mesmo não estando marcado na materialidade linguística, como ocorre em peças publicitárias de outras instituições, é possível perceber o atravessamento de outros discursos no educacional.

De maneira um pouco mais marcada, a também faculdade rio-pretense Unorp, Centro Universitário do Norte Paulista, ao divulgar sua unidade do shopping Cidade Norte, oferece a seu público-alvo "Conhecimento aliado à conveniência e praticidade".

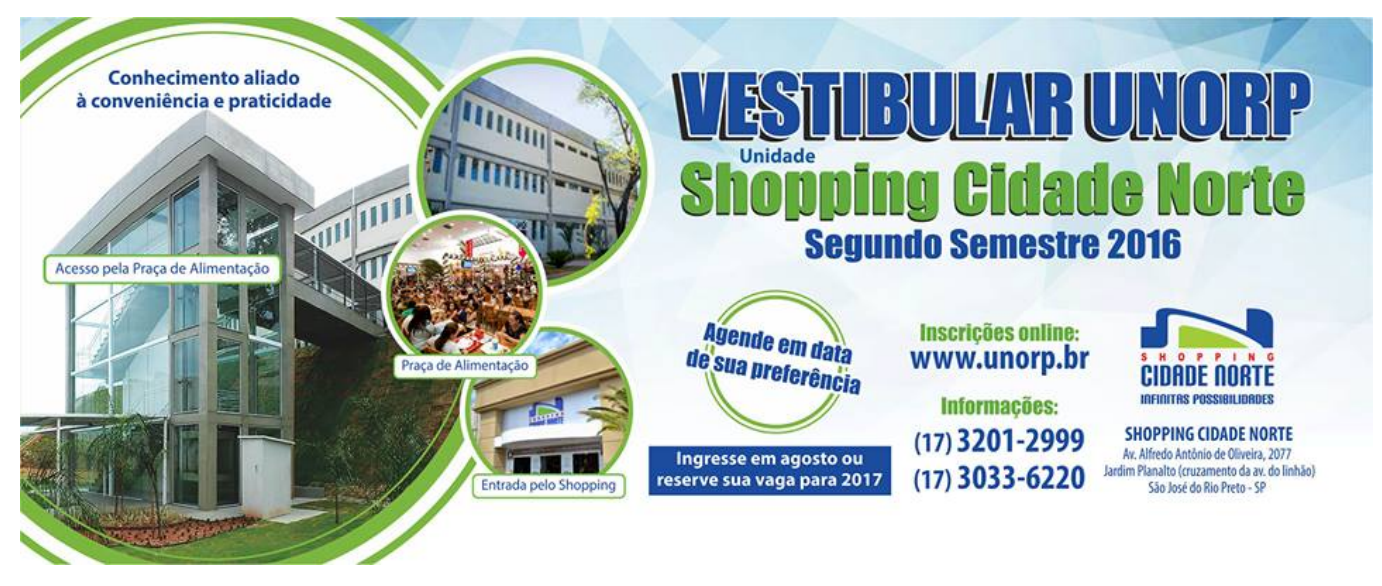

Página da UNORP no Facebook 9 .

Na tendência de movimentos presentes nas universidades particulares que buscam marcar o espaço educacional como um lugar de relações não-políticas, vincular uma

\footnotetext{
${ }^{9}$ Disponível em:

https://www.facebook.com/unorpRioPreto/photos/a.437630042943928.105871.437616349611964/12631 40220392902/?type=1\&theater. Acesso em 29 jun. 2017.
} 
faculdade a um espaço físico de um shopping reflete essa estetização comercial do próprio espaço da instituição de ensino. Assim como definidos por Padilha,

os shopping centers são, então, símbolos de uma sociedade que valoriza o espetáculo do consumo de bens materiais e de lazer-mercadoria, de uma sociedade que oferece a uma pequena parcela da população o direito a esse consumo e a esse lazer, enquanto exclui a maioria dessa mesma população. Assim, esses centros comerciais configuram-se como espaços de lazer alienado, influenciando de forma decisiva a construção da identidade social de cada um, tanto dos que frequentam esses espaços como também dos que não os frequentam, mas que, enfeitiçados pela publicidade e pela "cultura de consumo", desejam frequentá-lo. (PADILHA, 2006, p. 180)

A escola deve ser lugar de reflexão, de cultura, de conhecimento e de inclusão; portanto, vinculá-la a um espaço excludente e de lazer alienado sugere uma preocupação diferente da proposta na propaganda abaixo, com o seguinte slogan: "O seu futuro começa aqui". Relacionada com o imaginário do sujeito do discurso, a oferta de educação em shoppings, centros de consumo e, consequentemente, símbolos do capitalismo, demonstra fortemente o atravessamento de um discurso mercadológico. $O$ que deveria ser apresentado como um espaço propulsor de cultura e conhecimento, papel da escola, por transferência ou sobreposição do efeito metafórico, reflete em um discurso de conhecimento como centro de aquisição de mercadoria. Afirmar que o conhecimento oferecido pela instituição é aliado à conveniência e praticidade enfatiza ainda mais a finalidade da faculdade: a "venda" de produtos prontos, práticos e convenientes pacotes de conhecimento. Assim, tempo e espaço colaboram para a ressignificação do conceito de conhecimento empregado.

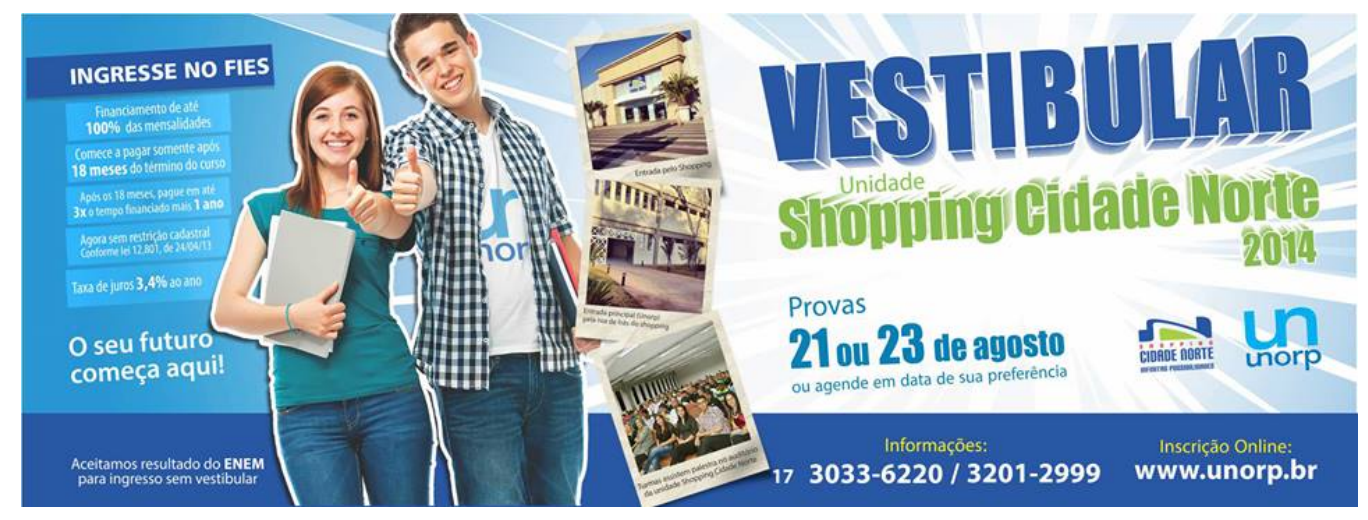

Página da UNORP no Facebook ${ }^{10}$.

É natural que, ao apresentar uma preocupação em estimular o consumo, haja facilidades referentes aos custos desse produto, o que justifica a presença das informações financeiras na propaganda acima: financiamento de até $100 \%$ das mensalidades; início do pagamento somente após 18 meses do término do curso; entre outros benefícios para o

\footnotetext{
${ }^{10}$ Disponível em:

https://www.facebook.com/unorpRioPreto/photos/a.437630042943928.105871.437616349611964/80229

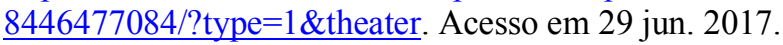


contratante. Por fim, o Centro Universitário da Fundação Educacional de Barretos, UNIFEB, divulga seus cursos oferecendo "Conhecimento que transforma a sua vida".

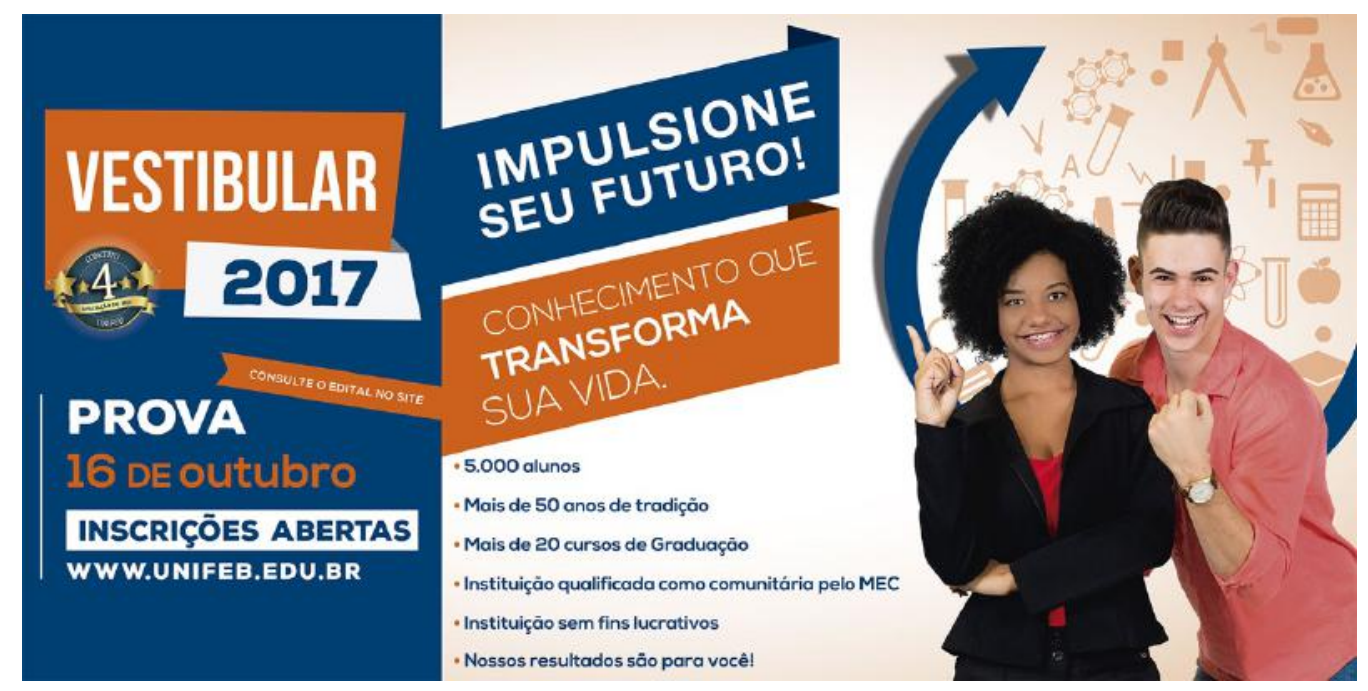

Página da UNIFEB no Facebook ${ }^{11}$.

Nessa propaganda, o discurso mercadológico emerge ao fazer uso de elementos que são de natureza emocional: o futuro profissional do sujeito interpelado pela peça publicitária. A interlocução individualizada é marca do discurso publicitário. Assim, o slogan "Impulsione seu futuro" produz um efeito de individualização do consumo dos produtos que, na sociedade contemporânea, são produzidos em série. Se comparada às demais propagandas, não há na peça publicitária acima marcas explícitas do apelo mercadológico, o que não implica sua neutralidade quanto à "venda" de seu produto, uma vez que algo que caracteriza o discurso publicitário é dirigir-se ao interlocutor, favorecendo um processo que produz um efeito de sentido de individualização do "consumo" dos cursos ofertados por essa instituição. O enunciado "No UNIFEB conhecimento transforma sua vida", por meio de um efeito metafórico, evoca imagens inscritas na memória discursiva do sujeito, ressignificando, assim, o conceito de conhecimento, apresentado como algo pronto e não como algo a ser construído continuamente, ou seja, apaga-se o conceito de conhecimento como processo.

\section{CONSIDERAÇÕES FINAIS}

Conforme procuramos demonstrar ao longo da presente abordagem, o deslizamento de sentidos dos enunciados deixa emergir, muitas vezes de forma não marcada na materialidade linguística, a questão do conhecimento como um produto tanto para o fornecedor quanto para o cliente. Por meio de uma reflexão fundamentada nos pressupostos teórico-metodológicos da Análise do Discurso de linha francesa, buscamos refletir sobre o modo como o sujeito, interpelado por uma ideologia e afetado pelo inconsciente, por estar posicionado em um tempo e espaço socialmente situados,

\footnotetext{
${ }^{11}$ Disponível em:

https://www.facebook.com/UnifebBarretos/photos/a.401220819892428.112146.142262155788297/13517 46044839896/?type=1\&theater. Acesso em 29 jun. 2017.
} 
apresenta seu discurso interligado entre o linguístico e o social, o que leva a uma interpretação materializada na/pela história. Nessa direção, o conceito de efeito metafórico mostrou-se relevante para as considerações realizadas, uma vez que, expondo a relação da língua e da historicidade no discurso, esse efeito desloca os sentidos dados à noção de conhecimento apresentada.

Nesse sentido, sinalizamos que, ao serem demarcados por uma ordem discursiva que estabelece quais serão os limites de determinado discurso, os dizeres analisados sugerem que o discurso das propagandas é atravessado por formações discursivas mercadológicas. O deslocamento de sentidos, que emerge na relação entre o dito e o nãodito, aponta que o conhecimento seja compreendido como produto e não como processo. Essa ideia de transferência de conhecimento, em detrimento do entendimento de conhecimento como construção, nos remete ao conceito de "Educação bancária" de Paulo Freire, em que o conhecimento adquirido dos professores é depositado nos alunos. Mesmo sendo empregado em contexto diferente, esse conceito de depósito de conhecimento é bastante incutido nos discursos das propagandas.

Assim, a partir da perspectiva da Análise do Discurso de linha francesa, pudemos notar como os efeitos metafóricos produzidos no discurso das propagandas, afetado por dizeres anteriores, ou seja, pela memória discursiva que faz parte de um processo histórico, assinalam a presença de um interdiscurso mercadológico contribuindo para a ocorrência de novos efeitos de sentido.

\section{REFERÊNCIAS}

DELA-SILVA, S.; CRUZ, J.S.A. "Eu tenho um fusca e um violão": sobre o discurso publicitário e a posição sujeito consumidor. ENTREMEIOS [Revista de Estudos do Discurso, on-line, www.entremeios.inf.br]. Programa de Pós-graduação em Ciências da Linguagem (PPGCL), Universidade do Vale do Sapucaí, Pouso Alegre (MG), v. 11, p. 17-34, jul.-dez. 2015. Disponível em: http://www.entremeios.inf.br/published/296.pdf. Acesso em 29 jun. 2017.

FERREIRA, M.C.L. O caráter singular da língua na Análise do Discurso. ORGANON, Instituto de Letras, Universidade Federal do Rio Grande do Sul, Porto Alegre, v. 17, n. 35, p. 189-200, 2003. Disponível em: http://seer.ufrgs.br/organon/article/view/30023. Acesso em 29 jun. 2017.

GASPARINI, E.N. A língua na Análise do Discurso. REVISTA DA ANPOLL, Centro de Comunicação e Expressão, Universidade Federal de Santa Catarina, Florianópolis, v. 1, n. 39, p. 62-68, jul.-ago. 2015. Disponível em: https://revistadaanpoll.emnuvens.com.br/revista/article/view/904. Acesso em 29 jun. 2017.

GREGOLIN, M.R. O acontecimento discursivo na mídia: metáfora de uma breve história do tempo. Em: GREGOLIN, M.R. (Org.). Discurso e Mídia: a cultura do espetáculo. São Carlos: Claraluz, 2003. p. 95-110. 
MAGAlHÃeS, I. Análise do discurso publicitário. REVISTA DA ABRALIN, Programa de Pós-Graduação em Linguística, Universidade Federal de Santa Catarina, Florianópolis, vol. 4, n. 1 e 2, p. 231-260, dez. 2005. Disponível em: http://revistas.ufpr.br/abralin/article/view/52650/32364. Acesso em 29 jun. 2017.

ORLANDI, E.P. Texto e discurso. Em: Interpretação, autoria, leitura e efeitos do trabalho simbólico. $6^{\mathrm{a}}$. ed. Campinas: Pontes, 2012. p. 52-62.

Análise de Discurso. Em: ORLANDI, E.P.; LAGAZZI-RODRIGUES, S. (Orgs.). Introdução às Ciências da Linguagem: discurso e textualidade. Campinas: Pontes, 2006.

Análise de Discurso: princípios e procedimentos. Campinas: Pontes, 2001. $\overline{\text { p. } 53-73 .}$

Discurso e leitura. 5a . ed. São Paulo: Cortez; Campinas: Ed. da UNICAMP, 2000.

PADILHA, V. Shopping center: a catedral das mercadorias. São Paulo: Bomtempo, 2006.

PÊCHEUX, M. Análise Automática do Discurso. Em: GADET, F.; HAK, T. (Orgs.). Por uma análise automática do discurso: uma introdução à obra de Michel Pêcheux. Trad. Bras. Campinas: Ed. da Unicamp, 1997. p. 61-161.

PÊCHEUX, M. Semântica e Discurso: uma crítica à afirmação do óbvio. Trad. Bras. $3^{\mathrm{a}}$. ed. Campinas: Ed. da Unicamp, 1997.

PEREIRA, R.C. Discurso e publicidade: dos processos de identificação e alteridade pela propaganda brasileira. 2006. Tese. Doutorado em Letras. Universidade Federal Fluminense, Instituto de Letras, 2006. Disponível em http://www.bdtd.ndc.uff.br/tde arquivos/23/TDE-2007-03-23T103332Z695/Publico/TeseRCPD.pdf. Acesso em 29 jun. 2017.

SAMPAIO, H. O setor privado de Ensino Superior no Brasil: continuidades e transformações. REVISTA ENSINO SUPERIOR UNICAMP, n. 4, p. 28-43, 2011. Disponível em: https://www.revistaensinosuperior.gr.unicamp.br/edicoes/ed04_outubro2011/05_ARTI GO_PRINCIPAL.pdf. Acesso em: 29 jun. 2017.

ZANDWAIS, A. Perspectivas da análise do discurso fundada por Michel Pêcheux na França: uma retomada de percurso. Santa Maria: UFSM, Programa de Pós-Graduação em Letras, 2009. 
Artigo recebido em: julho de 2017.

Aprovado e revisado em: dezembro de 2017.

Publicado em: maio de 2018.

\section{Para citar este texto:}

KAPP-BARBOZA, Aline Maria Miguel; GALLI, Fernanda Correa Silveira. O conhecimento como produto: uma análise discursiva das propagandas de centros universitários particulares. Entremeios [Revista de Estudos do Discurso, ISSN 21793514, on-line, www.entremeios.inf.br], Seção Estudos, Programa de Pós-Graduação em Ciências da Linguagem (PPGCL), Universidade do Vale do Sapucaí (UNIVÁS), Pouso Alegre (MG), vol. 16, p. 79-96, jan. - jun. 2018.

DOI: http://dx.doi.org/10.20337/ISSN2179-3514revistaENTREMEIOSvol16pagina79a96 